\title{
Identification of Glucocorticoid-inducible Cytochromes P-450 in the Intestinal Mucosa of Rats and Man
}

\author{
P. B. Watkins, ${ }^{\star \ddagger}$ S. A. Wrighton, ${ }^{\star}$ E. G. Schuetz, ${ }^{\star}$ D. T. Molowa, ${ }^{\star}$ and P. S. Guzelian \\ *Division of Clinical Toxicology and Environmental Medicine, Department of Medicine, \\ Medical College of Virginia, Richmond, Virginia 23298; and ${ }^{\ddagger}$ Department of Medicine, \\ McGuire Veterans Administration Hospital, Richmond, Virginia 23249
}

\begin{abstract}
We used monoclonal antibodies and complementary DNAs (cDNAs) to glucocorticoid-inducible liver cytochromes P-450 in rats ( $\mathrm{P}-450 \mathrm{p})$ and in man (HLp) to search for related cytochromes in intestinal mucosa. In rat enterocytes, we found two dexamethasone-inducible proteins related to the steroidinducible liver cytochromes $\mathbf{P}-\mathbf{4 5 0}$. Induction of these proteins in enterocytes was associated with increases in the amount of a P-450p-related messenger RNA and of erythromycin demethylase, an activity highly characteristic of P-450p and HLp. Similar studies on human jejunal enterocytes revealed a microsomal protein indistinguishable from HLp on immunoblots and an abundance of RNA hybridizing with HLp cDNA. In human enterocytes the specific concentration of the HLp-related cytochrome (measured immunochemically or as erythromycin demethylase activity) was similar to that found in human liver and could account for all of the CO-binding hemoprotein detected. We conclude that the intestinal mucosa contains prominent form(s) of cytochromes P-450 similar to liver cytochrome $\mathrm{P}-\mathbf{4 5 0 p}$ in their structure, function, and some regulatory characteristics.
\end{abstract}

\section{Introduction}

The cytochromes $\mathrm{P}-450$ are a multigene family of microsomal hemoproteins. These enzymes are most prominent in the liver where they play a vital role in the biotransformation of such exogenous compounds as drugs, pesticides, and carcinogens. More than 15 different polypeptide forms of cytochrome $\mathrm{P}-450$ have been purified from rat liver, each differing in primary structure and, in some cases, in substrate specificity and in response to prototypic inducers such as phenobarbital, 3-methylcholanthrene, and steroids (1). In certain instances, these cytochromes may catalyze the production of toxic or carcinogenic metabolites (2), whereas in other cases cytochromes $\mathrm{P}-450$ protect by facilitating the elimination of potentially harmful foreign substances (3).

Rats pretreated with the synthetic steroid pregnenolone$16 \alpha$-carbonitrile are resistent to the toxicity of many adminis-

Dr. Watkins' current address is Department of Medicine, University of Michigan Medical Center, Ann Arbor, MI 48109. Reprint requests should be sent to Dr. P. S. Guzelian, Division of Clinical Toxicology and Environmental Medicine, Medical College of Virginia, Box 267, MCV Station, Richmond, VA 23298.

Received for publication 16 March 1987 and in revised form 21 May 1987.

J. Clin. Invest.

(C) The American Society for Clinical Investigation, Inc. 0021-9738/87/10/1029/08 $\$ 2.00$

Volume 80, October 1987, 1029-1036 tered compounds (4). Furthermore, pretreatment with this "catatoxic" (4) steroid significantly reduces the incidence of liver carcinomas in rats exposed to dimethylnitrosamine (5). The molecular basis of this protective effect appears to involve induction of P-450p (6), the major form of cytochrome P-450 in the liver inducible by pregnenolone-16 $\alpha$-carbonitrile. Steroid hormones with glucocorticoid activity are also potent inducers of P-450p $(7,8)$ and of the cytochromes immunochemically related to $\mathrm{P}-450 \mathrm{p}$ that have been found in the livers of all mammals examined to date (9). This extends to human liver which contains HLp, a glucocorticoid-inducible cytochrome P-450 orthologous to P-450p $(10,11)$.

Cytochrome P-450-catalyzed biotransformations also occur in the intestinal mucosa where they may provide an important first line of defense against ingested toxins or carcinogens (12). However, little is known about the specific isozymes of cytochrome P-450 in the intestinal mucosa, their distribution within this tissue, or their regulation. This lack of information may be due to the difficulty in isolating microsomes from mucosal cells and to the belief that the concentrations of cytochrome $\mathrm{P}-450$ in this tissue are low as compared with those in liver.

Despite the intimate contact with potential carcinogens in the diet, the small bowel itself is remarkably resistent to spontaneous or experimental cancer formation (13). Having postulated a protective role for P-450p and HLp in liver (14), we examined rat and human jejunal mucosa for related cytochromes with the use of specific antibodies and cloned complementary DNAs (cDNAs) as molecular probes. Our results reveal that cytochromes related to $\mathrm{P}-450 \mathrm{p}$ are remarkably abundant constituents of the jejunal mucosa of rats and man.

\section{Methods}

Materials. Dexamethasone was purchased from Sigma Chemical Co., St. Louis, MO; nitrocellulose paper from Bio-Rad Laboratories, Richmond, CA; 3,3'-diaminobenzidine tetrahydrochloride from Pfaltz \& Bauer, Inc., Stamford, CT; Nick translation kits from Bethesda Research Laboratories, Gaithersburg, MD; and $\left[\mathrm{P}^{32}\right] \mathrm{CTP}$ (specific activity $>200 \mathrm{Ci} / \mathrm{mmol}$ ) from ICN Radiochemicals, Irvine, CA. All other reagents were of the highest purity commercially available.

Animals and treatments. Male Sprague-Dawley rats (250-275 g, Flow Laboratories, Inc., McLean, VA) were housed in pairs in wirebottom cages. They were given unlimited access to standard lab chow and tap water before the study, but only tap water during treatment intervals. Dexamethasone $(20 \mathrm{mg} / \mathrm{kg})$ suspended in corn oil was administered by gavage 24 and $2 \mathrm{~h}$ before decapitation. Control animals received corn oil alone. All animals were killed between 9 and 11 a.m.

Human subjects. Specimens of human liver and intestine were obtained from the operating room according to a protocol approved by the Committee for the Conduct of Human Research at the Medical College of Virginia. Patient numbers are used to designate liver specimens, some of which have been used in prior studies $(10,11,14)$. Patient 3, a 27-yr-old white male, became an organ donor after sustaining a severe head injury in an automobile accident. He was intoxi- 
cated (blood alcohol level was $0.22 \%$ ), and the only medications he received before surgery were vitamin $\mathrm{K}$ and potassium chloride. $\mathrm{Pa}$ tient 7 was a 42-yr-old white female who received no medications before hepatic lobectomy for metastatic colon cancer. Patient 9, a 36-yr-old white male, became an organ donor after rupturing a cerebral aneurysm. During the $24 \mathrm{~h}$ before surgery, he received dexamethasone $(200 \mathrm{mg})$, diphenylhydantoin $(200 \mathrm{mg})$, and amobarbital $(60$ $\mathrm{mg}$ ). Patient 10 was a 36-yr-old white female who underwent elective resection of a hepatic angioma. She received lorazepam, morphine sulfate, and cephazolin before surgery. Patient 12, a 46-yr-old white male, received no medications before hepatic lobectomy for metastatic colon cancer. Patient 14, a 50-yr-old white male, was given only a single $15-\mathrm{mg}$ dose of lorazepam before an exploratory laporatomy. Patient 17 was a 56-yr-old white male who became an organ donor shortly after incurring severe head trauma. His blood alcohol level on admission was $0.30 \%$ and $5 \mathrm{~h}$ before surgery he received intravenous dexamethasone $(10 \mathrm{mg})$ and diphenylhydantoin $(1 \mathrm{~g})$. He received furosemide $(100 \mathrm{mg})$ and thorazine $(100 \mathrm{mg})$ intraoperatively.

Samples of human intestine are designated in this report by letters A-K. Each of the patients A-F and H-K was morbidly obese, otherwise in good health, and taking no medications. Each patient received a single oral dose $(300 \mathrm{mg}$ ) of cimetidine the evening before surgery (as part of a separate, unrelated study). Patient $\mathrm{G}$ was an organ donor from whom historical details were unavailable.

Isolation of intestinal mucosa cells. All rats received ether anesthesia before decapitation. The segment of jejunum $(15 \mathrm{~cm})$ immediately distal to the pyloric valve was excised and mucosal cells were isolated in buffers containing citrate and EDTA according to the technique of Weiser (15) with minor modifications. Solutions " $A$ " and "B" were prepared as described (15) except phenylmethylsulfonylfluoride (40 $\mu \mathrm{g} / \mathrm{ml}$ final concentration) was added. The lumen of the freshly excised jejunal segments were flushed with $50 \mathrm{cc}$ of cold solution A. Each intestinal segment was ligated at its distal end and filled and drained twice with cold solution $A$. To isolate mucosal cells for immunochemical measurements, the segments were filled with solution $A$, incubated for $15 \mathrm{~min}$ at $37^{\circ} \mathrm{C}$, then refilled with warmed solution $\mathrm{B}\left(37^{\circ} \mathrm{C}\right)$. The open end was clamped and the filled segments were submerged in solution $B\left(37^{\circ} \mathrm{C}\right)$. The contents of each segment were drained and replaced with fresh solution $B\left(37^{\circ} \mathrm{C}\right)$ at $5,10,20,30$, and $50 \mathrm{~min}$. The mucosal cells dissociated from the intestinal lumen during each incubation were recovered by centrifugation $(900 \mathrm{~g}, 5 \mathrm{~min})$, which created five cell fractions that were numbered $1-5$ in the order obtained. The isolated cells were washed twice in iced solution " $C$ " $(16)$. This method has been shown to selectively remove mucosal cells, exclusive of interstitial and serosal cells, from the villus in a sequential manner beginning at the villus tip and progressing to the villus crypt (15). The total protein in each of the five enterocyte fractions was approximately equivalent.

For measurements of enzymatic activity, cells were harvested from jejunal segments as described above except that all solutions were maintained at $4^{\circ} \mathrm{C}$, the closed jejunal segments were vigorously agitated in solution B on a horizontal oscillating table, and only four enterocyte fractions (harvested at $5,10,20$, and $30 \mathrm{~min}$ ) were obtained. These enterocytes were washed in cold solution $C$ as described above. For hybridization analysis, RṆ was extracted from the initial enterocyte fraction (corresponding to $5 \mathrm{~min}$ incubation in cold solution B).

Human enterocytes were isolated by cutting the surgical specimen along the axis of the lumen to create a flat mucosal surface $(\sim 2 \times 2$ $\mathrm{cm}$ ) that was then swirled in solution $\mathrm{A}\left(4^{\circ} \mathrm{C}\right)$ for $1 \mathrm{~min}$, occasionally rubbing the mucosal surface with a gloved finger. Next, the tissue segment was incubated in $50 \mathrm{cc}$ of solution $\mathrm{A}\left(4^{\circ} \mathrm{C}\right)$ for $30 \mathrm{~min}$, and then transferred to a vessel containing $75 \mathrm{ml}$ of solution $B\left(4^{\circ} \mathrm{C}\right)$ that was swirled vigorously on a horizontal oscillating table for $10 \mathrm{~min}$. The dissociated cells were isolated as a single fraction and washed as described for rat intestinal cells.

Preparation of microsomes. Microsomes were prepared from rat and human liver by differential centrifugation (17). To prepare microsomes from washed rat and human enterocytes, we used a technique previously reported to yield high specific content of total CO-binding protein (16). Each enterocyte fraction (pooled from four rats or one human specimen) was suspended in $2.5 \mathrm{cc}$ of solution $\mathrm{C} \mathrm{(16)} \mathrm{and} \mathrm{was}$ disrupted by sonication ( $35 \mathrm{~s}$ at 35 setting of a dismembranator; Artek Systems Corp., Farmingdale, NY). The cell lysate was sedimented at $15,000 \mathrm{~g}$ for $10 \mathrm{~min}$. The supernatant was transferred to a conical plastic tube; iced $52 \mathrm{mM}$ calcium chloride solution $(2.5 \mathrm{ml})$ was added; and, after standing on ice for $15 \mathrm{~min}$, the microsomes were sedimented by centrifugation $(2,000 \mathrm{~g}$ for $15 \mathrm{~min})$. The pellet was resuspended in $2.5 \mathrm{ml}$ of solution " $\mathrm{D}$ " (16) and enzymatic and spectral assays were performed immediately. The remaining microsomes were stored at $-70^{\circ} \mathrm{C}$.

Immunoblot analyses. Immunoblots of intestinal and liver microsomes were carried out as previously described (18). Microsomal proteins were separated by electrophoresis in $10 \%$ sodium dodecyl sulfate-polyacrylamide gels (19) (30 mA per gel, $4 \mathrm{~h}$ ). The resolved proteins were electrophoretically transferred to nitrocellulose filters under conditions that have been shown to result in complete transfer from the gel of up to $40 \mu \mathrm{g}$ of microsomal protein (18). The remaining protein binding sites were blocked by overnight incubation in phosphate buffered saline $\left(25^{\circ} \mathrm{C}\right)$ containing $3 \%$ bovine serum albumin and $10 \%$ calf serum. Next, the filters were treated sequentially with the monoclonal antibody $(1 \mathrm{~h})$ followed by peroxidase-conjugated antimouse IgG ( $30 \mathrm{~min}$ ) with extensive washing in cold phosphate buffered saline after each incubation. The immunoreactive proteins were visualized by incubating the filters in a solution containing 3,3'-diaminobenzidine tetrahydrochloride and hydrogen peroxide $(0.06 \%)$. In some studies, the integrated optical density of each stained band was determined by scanning with a densitometer (Carl Zeiss, Inc., Thornwood, NY). By assaying microsomes prepared from villus tip cells isolated from dexamethasone-treated rats, we demonstrated that the optical density of the immunoreactive bands was directly proportional to the quantity of microsomal protein applied to the gel over a wide range $(5.0-40 \mu \mathrm{g})$. The microsomal concentration of immunoreactive protein in each cell population was calculated as the ratio of band intensity on immunoblots (expressed in arbitrary units) divided by the amount of microsomal protein applied to the gel. Ratios were determined in triplicate for each cell fraction and the average was expressed as a percent of the highest of the average values obtained for all of the cell fractions. To optimize comparability of treatments, a single immunoblot was used for immunoquantitations of microsomes prepared from the cell populations for both treated and control rats (10 samples).

The concentration of 13-7-10-reactive protein in human intestinal microsomes was estimated by assuming that the affinity of this monoclonal antibody for the intestinal cytochrome and for purified liver cytochrome HLp was equal. Separation of microsomal proteins by electrophoresis was temporarily interrupted after $2 \mathrm{~h}$. Amounts of purified HLp known to give linear densitometric values on developed immunoblots (1.0-4.0 pmol) were added to the gel wells and the current resumed $(2 \mathrm{~h})$. From the integrated density of the HLp standards, the concentration of 13-7-10-reactive protein in human intestinal microsomes was calculated as nanomoles of immunoreactive protein per milligram of microsomal protein.

Antibodies and purified cytochromes P-450. P-450p and HLp were purified from rat and human livers, respectively, as previously described $(6,10)$. The monoclonal antibody $13-7-10(20)$ was a generous gift from Dr. Pierre Kremers, Institute of Pathology Batiment B23 4000 Sart-Tilman Liege, Belgium. The 1G8 monoclonal antibody was prepared by injecting $50 \mu \mathrm{g}$ of purified P-450p (in $0.1 \mathrm{ml}$ of $50 \mathrm{mM}$ potassium phosphate [pH 7.5], $50 \mathrm{mM}$ EDTA, $20 \%$ glycerol buffer combined 1:1 with Freunds' complete adjuvant) into five virus-free female Balb/C mice (15-18 g, Charles River Breeding laboratories, Inc., Wilmington, MA). After $21 \mathrm{~d}$, a boost of $20 \mu \mathrm{g}$ of P-450p was administered. $6 \mathrm{~d}$ later, blood samples were pooled and serum was assayed for the presence of an antibody by an enzyme-linked immunoabsorbent assay (ELISA). The final $20 \mu \mathrm{g}$ i.v. boost was performed $3 \mathrm{~d}$ before fusion. Spleen cells from one immunized mouse were fused with P3-X63-AG8 multiple myeloma cells and the resulting 
hybridoma was expanded in vitro. Individual clones were tested for antibody production by ELISA, allowed to expand, and then injected into female Balb/C mice $\left(5 \times 10^{6}\right.$ cells per mouse interperitoneally) that had been primed $2 \mathrm{wk}$ previously with pristane $(0.5 \mathrm{ml}$ i.p.). The asitic fluid was collected 9 and $14 \mathrm{~d}$ later, and, after cells were removed by centrifugation, was stored at $-70^{\circ} \mathrm{C}$.

$R N A$ isolation. The method of Chirgwin et al. (21) was used to isolate RNA from rat and human intestinal mucosal cells. Approximately $1 \mathrm{~g}$ of enterocytes (wet weight) was combined with $15 \mathrm{ml}$ of an 10-mM Tris- $\mathrm{HCl}$ buffer (pH 7.4) containing $4 \mathrm{M}$ guanidine thiocyanate and $7 \% \beta$-mercaptoethanol and lysed with a polytron (Brinkmann Instruments Co., Westbury, NY) for $20 \mathrm{~s}$. The suspension was mixed with $1.6 \mathrm{ml}$ of $20 \%$ sarcosyl, passed twice through a 22-gauge needle, and divided between two $15-\mathrm{ml}$ sterile quickseal tubes. Cesium chloride $(4.5 \mathrm{ml})$ was layered under the supernatant and the RNA was sedimented by centrifugation $(100,000 \mathrm{~g})$ for $16 \mathrm{~h}$ at $25^{\circ} \mathrm{C}$. The supernatant was removed, and the clear pellet was washed with ethanol and resuspended in $0.5 \mathrm{ml}$ of sterile water. Total RNA content was estimated by absorbance at $260 \mathrm{~nm}$. For all preparations, the ratio of the absorbances at $260 / 280 \mathrm{~nm}$ exceeded 1.8. Poly $\left(\mathrm{A}^{+}\right) \mathrm{RNA}$ was prepared by passing the total RNA through two cycles of oligo(dT)-cellulose chromatography.

Northern blot analyses. Total RNA or poly $\left(\mathrm{A}^{+}\right)$RNA from liver and intestine was subjected to electrophoresis in $1.0 \%$ agarose gels with $10 \mathrm{mM}$ sodium phosphate buffer containing $1.1 \mathrm{M}$ formaldehyde, and then transfered by blotting onto nitrocellulose. The nitrocellulose sheets were baked in vacuo for $2 \mathrm{~h}$, incubated with salmon sperm DNA, and then hybridized for $12 \mathrm{~h}$ with cDNA labeled with ${ }^{32} \mathrm{P}$ by nick translation. The filters were washed twice with $2 \times$ standard saline citrate (SSC), $0.1 \%$ sodium dodecyl sulfate at $25^{\circ} \mathrm{C} \mathrm{(15} \mathrm{min} \mathrm{each),} \mathrm{and}$ once with $0.1 \times \mathrm{SSC}, 0.1 \%$ sodium dodecyl sulfate for $15 \mathrm{~min}$ at $25^{\circ} \mathrm{C}$ followed by $15 \mathrm{~min}$ at $60^{\circ} \mathrm{C}$. The hybridized bands were visualized by autoradiography. Preparation of the pDex 12 and Hp55s cDNAs have been previously described $(9,11)$. Chicken $\beta$-actin cDNA (22) was a gift from Lola M. Reid, Albert Einstein Medical School, 1300 Morris Park Ave., Bronx, NY 10461.

Other assays. Erythromycin demethylase activity was determined by colorimetric measurement of formaldehyde formed $(9,23)$. Alkaline phosphatase activity was assayed in mucosal cell lysate $(10 \mu \mathrm{g})$ with $\rho$-nitrophenol-phosphate serving as substrate (15). Protein concentration was determined colorimetrically (24). Total CO-binding hemoprotein was determined by difference spectroscopy (25).

\section{Results}

Identification of $P-450 p$-related cytochromes in intestinal mucosa. With the protocols described in Methods it was possible to reproducibly prepare microsomes from villus tip cells from $15 \mathrm{~cm}$ of rat small bowel (immediately distal to the pyloric valve) or from $2 \mathrm{~cm}$ of human jejunum. Villus tip cell microsomes prepared from the jejunum of an organ donor (patient G) readily catalyzed the demethylation of erythromycin (Fig. 1), an activity highly characteristic of P-450p and HLp in hepatic microsomes from rats and humans, respectively $(10,26)$. Furthermore, this enzymatic activity could be inhibited (75\%) by incubating the human intestinal microsomes with anti-P. $450 \mathrm{p} \mathrm{IgG}$, an antibody that reacts with hepatic glucocorticoidinducible cytochromes of several mammals (9), including humans (10) (Fig. 1). This result mirrors the immunoinhibition of erythromycin demethylase activity in human liver microsomes (10). In contrast, preincubation of human intestinal microsomes with nonimmune IgG or with antibodies raised to other forms of cytochrome P-450 (P-450c or P-450b [27]) failed to inhibit erythromycin demethylase activity significantly (Fig. 1). Microsomes prepared from rat jejunum enter-

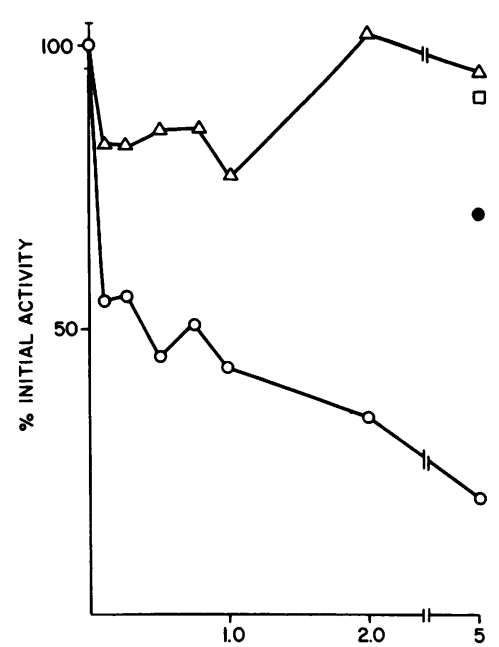

$\mathrm{mg} \mathrm{Ab/mg} \mathrm{MICROSOMAL} \mathrm{PROTEIN}$
Figure 1. Inhibition of erythromycin demethylase activity in enterocyte microsomes from patient G by anti-P-450p IgG. Antibodies were added in the indicated amounts to standard erythromycin demethylation reaction mixtures $\left(15 \mathrm{~min}, 37^{\circ} \mathrm{C}\right)$. The results are given as percentage of a control incubation containing no antibody $(0.90 \mathrm{nmol}$ formaldehyde formed $/ \mathrm{min}$ per $\mathrm{mg}$ of microsomal IgG; $\square$, anti-P-450c; •, anti-P-450b; $O$, anti-P450p. protein). $\triangle$, Nonimmune

ocytes also catalyzed erythromycin demethylation, and this activity was inhibited similarly by anti-P-450p IgG (data not shown).

For immunochemical analysis, intestinal microsomes prepared from the villus tip cells were subjected to electrophoresis in sodium dodecyl sulfate-polyacrylamide gels and analyzed on immunoblots developed with anti-P-450p IgG. In both the rat and human samples, this polyclonal antibody reacted with only a single protein band that comigrated with purified P-450p (data not shown). These experiments were extended by developing immunoblots with a monoclonal antibody, 1G8, that reacts with purified P-450p (Fig. $2 A$, lane $P-450 p$ ) but not with purified HLp (Fig. $2 A$, lane $H L p$ ). $1 \mathrm{G} 8$ reacted with an intestinal microsomal protein in rat villus tip cells, producing a single band (Fig. $2 A$, lane $I n t$ ) indistinguishable from that of purified P-450p or of immunoreactive P-450p in liver microsomes prepared from untreated male rats (Fig. $2 A$, lane $M L$ ). As we observed previously with the use of form-specific antiP-450p IgG (9), 1 G8 recognized no proteins in liver microsomes prepared from untreated female rats (Fig. $2 A$, lane $F L$ ). In another study (28), we have shown that liver microsomes of male rats contain, in addition to $\mathrm{P}-450 \mathrm{p}$, a second glucocorticoid-inducible protein recognized by 1 G8 (not readily appreciated from Fig. $2 A$ ); however, repeated analyses of the immunoblots of intestinal microsomes did not reveal a second 1G8reactive protein. Next, we tested a monoclonal antibody, 13-7-10, that does not recognize purified P-450p (Fig. $2 B$, lane $P-450 p$ ) but does react with HLp (Fig. $2 B$, lane $H L p$ ). Monoclonal antibody 13-7-10 recognized a male rat intestinal protein (Fig. $2 B$, lane marked Int) although its mobility was not the same as the 13-7-10-reactive protein found in male rat liver (Fig. $2 B$, lane $M L$ ). Rather, the mobility of the 13-7-10reactive protein in the intestine matched that of a glucocorticoid-inducible 13-7-10-reactive protein in the liver of female rats (28) (Fig. $2 B$, lane $F L$ ). When the lane containing the blotted intestinal proteins was cut lengthwise and the halves separately developed with 1 G8 or 13-7-10, the mobilities of the proteins identified in these "mirror image" blots were identical (not shown). From these results we concluded that rat intestine contains one or more proteins functionally and immunochemically related to $\mathrm{P}-450 \mathrm{p}$.

Immunoblots of microsomes prepared from human villus 

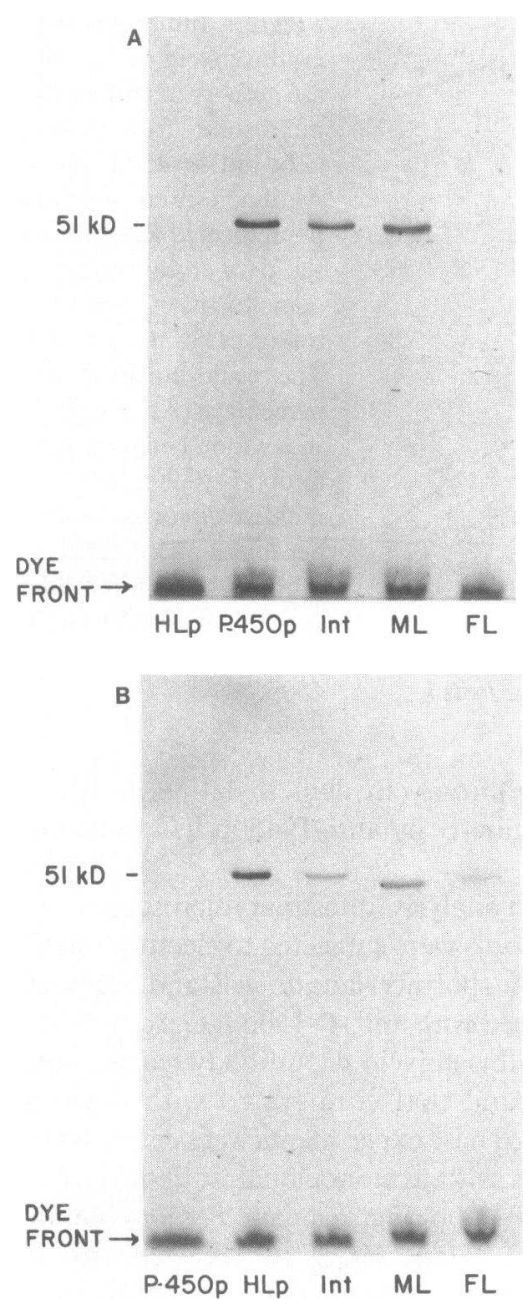

Figure 2. Proteins reactive with the $1 \mathrm{G} 8$ or 13-7-10 monoclonal antibodies in microsomes prepared from rat liver or intestine. Purified HLp (lane $H L p, 1$ pmol) and P-450p (lane $P-450 p, 1 \mathrm{pmol})$ and microsomes prepared from the villus tip enterocytes isolated from the intestine of an untreated male rat (lane Int, $50 \mu \mathrm{g}$ ) and liver of untreated male (lane $M L, 50 \mu \mathrm{g}$ ) and female (lane $F L, 50 \mu \mathrm{g}$ ) rats were subjected to electrophoresis in a polyacrylamide gel containing sodium dodecyl sulfate. The separated proteins were transferred electrophoretically to nitrocellulose and the resulting blots were developed with the monoclonal antibodies $1 \mathrm{G8}(A)$ or $13-7-10(B)$, as described in Methods.

tip cells revealed no proteins that reacted with the 1G8 monoclonal antibody (data not shown), and we have observed that microsomes prepared from human liver also lack 1G8-reactive proteins (unpublished observations). In contrast, analysis of the human intestinal microsomes on immunoblots developed with the 13-7-10 antibody revealed in each of four patients a single well-defined band (Fig. 3, lanes $A-D$ ) that co-migrated

Figure 3. Proteins reactive with the 13-7-10 monoclonal antibodies in microsomes prepared from human intestine and liver. Purified HLp (lane $H L p, 1.0 \mathrm{pmol}$ ) and microsomes prepared from the intestinal villus tip cells of four patients (lanes $A-D, 25 \mu \mathrm{g})$ and the liver of patient 7 (lane liver, $25 \mu \mathrm{g}$ ) were subjected to immunoblot analysis and developed with 13-7-10, as described in Methods.

with purified HLp (Fig. 3, lane $H L p$ ) and with immunoreactive HLp in human liver microsomes (Fig. 3, lane liver). Immunoblot analysis of enterocyte microsomes prepared from patients E-K also revealed in each a 13-7-10-reactive protein that was indistinguishable from HLp (not shown). Furthermore, the intensity of the bands produced by enterocyte microsomes was similar in all ten patients studied and was comparable with that produced by an identical amount $(25 \mu \mathrm{g})$ of human liver microsomes (Fig. 3). We used quantitative analysis of immunoblots to measure the amounts of 13-7-10-reactive protein in human enterocyte microsomes, taking the assumption that 13-7-10 has equal affinity for the proteins it identifies in intestine and liver (HLp). Calculated in this way (Table I) the specific concentration of 13-7-10-reactive protein in the villus tip cells from four patients (A-D) is similar to the specific concentration of immunoreactive HLp measured in the livers of four patients (none of whom received medications demonstrated to induce HLp [10]). Furthermore, we found comparable values for erythromycin demethylase activities in the same samples of liver and intestinal microsomes (Table I). Indeed, the specific concentration of 13-7-10-reactive protein in intestinal villus tip cells actually exceeds the total concentration of cytochrome P-450 measured as CO-binding hemoprotein (Table I). In the liver, however, the concentration of immunoreactive HLp accounts for $\sim$ one-fifth of the CObinding hemoprotein present.

Induction of P-450p-related cytochromes in rat intestinal mucosa. Next, we investigated whether glucocorticoids could induce the intestinal protein(s) immunochemically and functionally related to P-450p and HLp. Enterocytes from treated and control animals were dissociated from jejunum segments in five sequential cell fractions. Alkaline phosphatase activity was high in the cell lysate of fraction $1(1.40 \mathrm{U} / \mathrm{mg})$, in good agreement with that reported for villus tip cells (15). The alkaline phosphatase activity we obtained in cell fraction $5(0.11$ $\mathrm{U} / \mathrm{mg}$ ) is consistent with cells from the "crypt zone" (15). Treatment of rats with dexamethasone resulted only in a slight diminution of alkaline phosphatase activity in each cell fraction when compared with control (Fig. $4 A$ ). Therefore, it can be concluded that enterocyte fractions 1 and 5 isolated from both treated and untreated rats were highly enriched in cells from the villus tip and crypt regions, respectively (Fig. $4 \mathrm{~A}$ ).

When microsomes prepared from each cell fraction from

Table I. Comparison of Human Liver and Intestine Microsomes for Some Parameters of Cytochromes P-450p and HLp

\begin{tabular}{lcr}
\hline & Jejunum & \multicolumn{1}{c}{ Liver } \\
\hline 13-7-10-Reactive protein ( $\mathrm{pmol} / \mathrm{mg})$ & $70 \pm 20$ & $65 \pm 20$ \\
Erythromycin demethylase activity & & \\
$\quad(\mathrm{nmol} / \mathrm{min} \mathrm{per} \mathrm{mg})$ & $1.12 \pm 0.12$ & $0.95 \pm 30$ \\
CO-binding hemoprotein $(\mathrm{pmol} / \mathrm{mg})$ & $55 \pm 16$ & $350 \pm 40$ \\
\hline
\end{tabular}

Microsomes were prepared from the villus tip cells of four patients (A, B, D, and E) and from the liver specimens from four patients $(3,7,12$, and 14). The concentration of 13-7-10-reactive protein was determined by quantitative immunoblots with purified HLp as standards; erythromycin demethylase activity, in standard incubation mixtures; and total cytochrome P-450, spectrally as CO-binding hemoprotein (see Methods). Results given are the mean of the single values obtained for each patient \pm SD. 

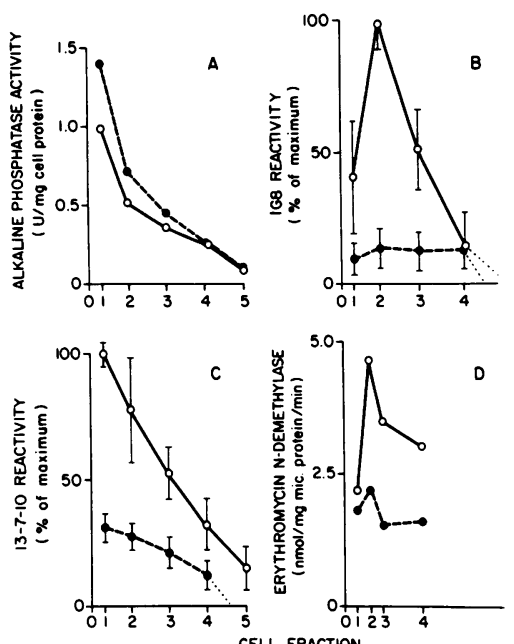

CELL FRACTION
Figure 4. The effect of dexamethasone treatment on alkaline phosphatase activity, microsomal reactivity with $1 G 8$ and 13-7-10, and erythromycin demethylase activity in rat enterocytes. In this representative experiment, $10 \mathrm{~cm}$ of proximal jejunum were excised from each of four untreated male rats and four dexamethasonetreated rats, and mucosal cells were dissociated in five sequential fractions from the villus tip (fraction 1) to the crypt (fraction 5) regions (see Methods). The following assays were performed, as described in Methods, on each of these enterocyte fractions: $(A)$ alkaline phosphatase activity ( $1 \mathrm{U}$ of activity is $1 \mu \mathrm{mol}$ of $\rho$-nitrophenol per $15 \mathrm{~min}$ incubation); $(B$ and $C$ ) $1 \mathrm{G} 8$ and 13-7-10 reactivity, respectively, determined in microsomes by quantitative immunoblotting (mean \pm SD of three determinations expressed as the percent of maximal reactivity obtained for any enterocyte fraction: dotted lines represent values below the lower limit of accurate quantitation). To assay erythromycin demethylase activity $(D)$, jejunal segments were excised from other groups of rats and enterocytes were dissociated at $4^{\circ} \mathrm{C}$ rather than at $37^{\circ} \mathrm{C}$ into four sequential fractions (see Methods). From the alkaline phosphatase activity of the fractions (1-1.60 U/mg; 2-1.15 U/mg; 3-0.80 U/mg; 4-0.45 U/mg), erythromycin demethylase activities $(D)$ were aligned along the horizontal axis to correspond to previously described fractions. $-\mathrm{O}-$, Dexamethasone; - -,-- , control.

control or treated rats were analyzed on immunoblots developed with either 1G8 or 13-7-10, only a single band was observed (data not shown). Because the immunoreactive intestinal proteins have not been purified for use as standards, we measured the immunoreactive proteins as the integrated density of the bands produced on immunoblots containing the same amounts of enterocyte microsomal protein (see Methods). In control animals, the amounts of 1G8-reactive protein (Fig. $4 \mathrm{~B}$ ) were the same among the enterocyte populations (except in the crypt region, fraction 5 , where reactive protein was detectable but could not be quantitated). In contrast, there was a gradient in the amounts of 13-7-10-reactive protein in the same samples, the highest concentration being found in the villus tip cells (Fig. $4 \mathrm{C}$ ). Dexamethasone treatment increased by as much as 10-fold the amounts of 1G8reactive protein, but only in the midportion of the villus (highest in fraction 2) and not in fractions 4 and 5 (Fig. 4 B). In contrast, the 13-7-10-reactive protein was induced three- to fourfold in each fraction, including fraction 5 (Fig. $4 C$ ). These results, confirmed in duplicate experiments, suggest that 1G8 and 13-7-10 likely identify different glucocorticoid-inducible proteins in rat enterocytes.

We were unable to detect microsomal erythromycin demethylase activity in the mucosal cells harvested by the method of Weiser (15) (data not shown). Therefore, we harvested enterocytes at $4^{\circ} \mathrm{C}$ and found that the alkaline phosphatase activities of the initial and final (fourth) fractions were
1.60 and $0.45 \mathrm{U} / \mathrm{mg}$, respectively. By comparing the respective alkaline phosphatase activities in the five cell fractions obtained by the standard technique (Fig. $4 \mathrm{~A}$ ), we concluded that at $4^{\circ} \mathrm{C}$ cells had not been harvested from the crypt region. Microsomal erythromycin demethylase activity was readily detected in mucosal cells obtained at $4^{\circ} \mathrm{C}$ (Fig. $4 \mathrm{D}$ ) and was induced by dexamethasone treatment (twofold) although not in proportion to the increases in 1G8 (10-fold) or 13-7-10 (threefold) immunoreactive proteins. Enzyme activity was inhibited $(>80 \%)$ when enterocyte microsomes from control or dexamethasone-treated rats were incubated with anti-P-450p IgG (data not shown). Because the monoclonal antibodies do not block catalytic activity in liver microsomes (unpublished results), we were unable to test directly which intestinal protein(s) catalyzed erythromycin demethylation. However, the erythromycin demethylase activity along the villus appears to correlate better with the amount of 1G8-reactive proteins (Fig. 4).

Identification of P-450p-related messenger RNA (mRNA) in intestinal mucosa. RNA extracted from intestinal villus tip cells of untreated and dexamethasone-treated rats was analyzed on Northern blots hybridized with pDex 12 (9), a 1.2-kilobase (kb) cDNA probe encoding the $3^{\prime}$ half of P-450p mRNA. This cDNA probe hybridized with RNA species of approximately the same size $(2.1 \mathrm{~kb})$ in enterocyte RNA and in liver RNA extracted from untreated male rats (Fig. 5). Dexamethasone treatment reproducibly increased the amount of pDex 12-hybridizable RNA in the intestine (Fig. 5). This effect of dexamethasone was selective inasmuch as rehybridization of this blot with a $\beta$-actin cDNA gave signals that were of equal intensity in the two intestinal RNA samples (data not shown).

In a similar experiment, human RNA extracted from the villus tip cells of two patients ( $E$ and $F$ ) and poly $\left(\mathrm{A}^{+}\right)$RNA prepared from the livers of two patients (10 and 9) was hybridized on a Northern blot with Hp55s (11), a 170-basepair cDNA representing the $5^{\prime}$ region of HLp mRNA (11). This cDNA probe hybridized with two species of RNA (Fig. $6 \mathrm{~A}$ ). The mobilities of the hybridizing RNA species in the intestine were the same as those for the human liver RNA (Fig. $6 \mathrm{~A}$ ). Because the hybridization affinity to Hp55s is identical between the two liver RNA species, we have suggested that this observation likely represents transcription of a single gene with

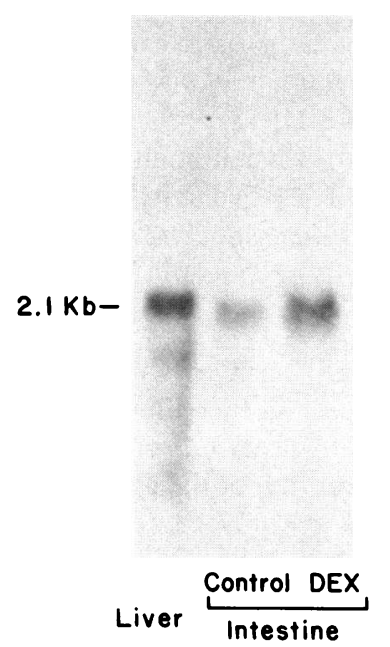

Figure 5. Dexamethasone induction of rat intestinal RNA hybridizing with pDex 12. In this representative Northern Blot, total RNA $(50 \mu \mathrm{g})$ was extracted from the liver of an untreated male rat (lane liver) and from the intestinal villus tip cells of untreated (lane control) and dexamethasone-treated (lane Dex) male rats. The RNA was processed by electrophoresis in an agarose gel, transferred to nitrocellulose, hybridized with $\left[{ }^{32} \mathrm{P}\right] \mathrm{pDex} 12$, and visualized by autoradiography, as described in Methods. 

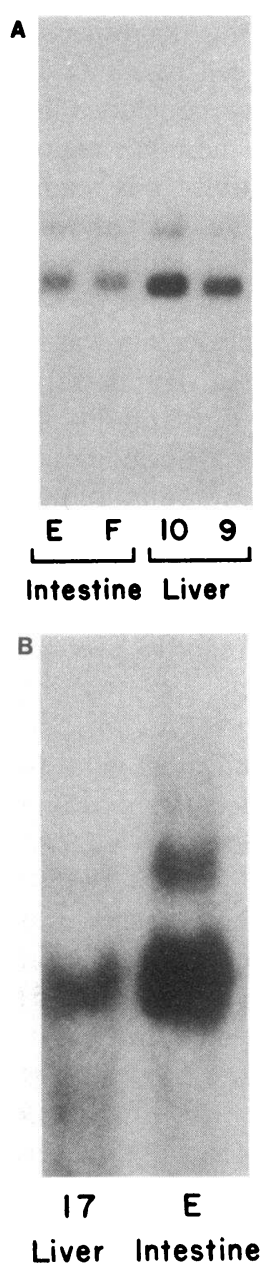

accompanied by the appearance of a protein in enterocyte microsomes indistinguishable on immunoblots from the major phenobarbital-inducible cytochrome (P-450b [27]) present in the liver. Similarly, administration of 2,3,7,8-tetrachlorodibenzo- $p$-dioxin to rats results in the appearance of $P-450 \mathrm{c}$ (27) in liver and of a protein in the intestinal mucosa that is immunochemically indistinguishable from $P-450 \mathrm{C}$ (32). In aggregate, these data suggest that as a portal of entry into the body, the intestine contains representatives of several of the families of liver cytochromes P-450. Moreover, we are unaware of previous reports on human intestinal cytochromes $P-450$. The human intestinal cytochrome we found matches human liver cytochrome HLp in its reactivity with 13-7-10 (Fig. 2), its mobility in polyacrylamide gels (Fig. 2), and its ability to catalyze erythromycin $N$-demethylation (Fig. 1, Table I). Furthermore, human intestinal RNA species intensely and selectively hybridized to Hp55s, a cDNA that corresponds to the $5^{\prime}$ end of the mRNA that encodes HLp (Fig. 6 $A$ and $B$ ).

Rat liver contains multiple proteins (28) and mRNAs (33) related to $P-450 p$. Evidence presented here suggests that the rat enterocyte also may contain multiple "P-450-like" proteins rather than a single protein reactive with both the $1 \mathrm{G8}$ and the 13-7-10 monoclonal antibodies. First, the magnitude of dexamethasone induction of the 1G8-reactive protein (10-fold) was considerably greater than the degree of induction of the 13-7-10-reactive protein (threefold) (Figs. $4 B$ and $C$ ). Furthermore, after treatment with dexamethasone, the highest specific content of the 13-7-10-reactive protein was found in cells harvested from the tip of the villus, whereas the greatest reactivity with $1 \mathrm{G8}$ was found in a population of cells located closer to the intestinal crypts (Figs. $4 B$ and $C$ ). Lastly, we have observed that intestinal microsomes rapidly lose their reactivity with $1 \mathrm{G} 8$ upon storage at $4^{\circ} \mathrm{C}$, whereas reactivity with $13-7-10$ is stable (unpublished observations). It is likely that one or both of the $\mathrm{P}-450 \mathrm{p}$-related intestinal proteins are functional cytochromes $\mathrm{P}-450$ because erythromycin demethylase activity was inhibited by anti-P-450p IgG and was induced in the enterocyte microsomes by dexamethasone treatment (Fig. 4). Even though the intestinal P-450p-related cytochromes and their corresponding mRNAs (Fig. 5) are induced by dexamethasone, as is $P-450 p$ in rat liver $(9,18)$, purification and sequencing of the intestinal cytochromes identified in this report will be required for definitive proof of their identity.

It is the accepted notion that intestinal crypt cells are "undifferentiated" (34). For example, intestinal crypt cells contain neither detectable CO-binding hemoprotein nor immunoreactive P-450b (16). Furthermore, unlike hepatocytes or villus cells, crypt cells do not respond to phenobarbital with induction of P-450b (16). In contrast, we found that 1G8-reactive and 13-7-10-reactive proteins were detectable in cells harvested from the crypt zone in untreated animals (although the amounts of both proteins were too low to quantitate). Moreover, 13-7-10-reactive proteins were induced by dexamethasone in crypt cells (Fig. $4 C$ ) implying that the receptor postulated to mediate induction of glucocorticoid-inducible cytochromes in rat liver (8) may be intact and operational. It is unlikely that the induction of 13-7-10-reactive protein detected in the crypt region represented contamination with villus cells because the alkaline phosphatase activity in the crypt cell population was low (Fig. 4) and there was a threefold increase in the concentration of 13-7-10-reactive protein 
along the entire villus to crypt gradient (Fig. $2 B$ ). Because expression of $\mathrm{P}-450 \mathrm{p}$ protein in the liver of untreated rats is restricted to the adult (35), crypt cells should be examined for other differentiated functions.

Although it is widely believed that the specific content of cytochrome P-450 in liver far exceeds that in intestinal mucosa, our data suggest that this is not the case for HLp-related cytochrome(s) in man. The specific content of the intestinal cytochrome in villus tip cells, measured as erythromycin demethylase activity or immunochemically as 13-7-10-reactive protein, was comparable with that observed in the livers of patients (Table I), and the concentration of HLp-related RNA was significantly higher in the enterocyte (Fig. $6 B$ ). Indeed, the concentration of the intestinal cytochrome measured immunochemically exceeded measurements of total CO-binding hemoprotein in microsomes prepared from human villus tip cells. This discrepancy between holocytochrome and immunoreactive protein may reflect true excess apoprotein in enterocytes, overestimation of apoprotein by immunochemical techniques, or underestimation in vitro of holocytochrome P-450 concentration in intestinal mucosa in vivo. Although it is possible that preoperative fasting, obesity, or treatment with cimetidine influenced the regulation of this intestinal cytochrome, we conclude that the HLp-related protein appears to be the major cytochrome P-450 in human jejunal mucosa.

Finding an abundant P-450p-related cytochrome in human jejunal mucosa enhances the idea of the intestine as a clinically important site of metabolism. For example, although des- $N$-methyl erythromycin is formed by liver P-450p after erythromycin is administered intravenously to rats, this metabolite is more abundant in the intestinal lumen than it is in bile (68 and 55\%, respectively, of the total erythromycin present [36]). The intestinal cytochromes identified in this report would account for continued metabolism of erythromycin entering the intestinal lumen either in bile or by nonbiliary pathways (37). This is likely to be clinically important because des- $N$-methyl erythromycin is less biologically active and more poorly absorbed from the digestive tract than is erythromycin $(36,38)$ and fecal excretion is the major route of elimination for erythromycin $(36,38,39)$. The pronounced loss in bioavailability of orally administered erythromycin, which is not explained by "first pass" liver metabolism (40), may also be attributed in part to intestinal HLp. Finally, since HLp is closely related, or identical, to P-450NF $(41,42)$, a human liver cytochrome $\mathrm{P}-450$ recently characterized by Guengerich et al., the substrate specificity of HLp also likely includes nifidepine (41), aldrin (41), quinidine (43), and endogenous steroid hormones (41). The finding of HLp-related cytochromes in high specific concentrations in human jejunal mucosa should prompt a reevaluation of the role played by intestinal metabolism in the fate of many clinically important compounds.

\section{Acknowledgments}

We wish to thank Lauren Cunningham for her excellent secretarial assistance in the preparation of this manuscript.

This research was supported by grants GM37498-01 and AM37261-01 from the National Institutes of Health, and by gifts from the Virginia Environmental Endowment. Dr. Watkins received support from a Veterans Administration Associate Investigator Award. Dr. Guzelian was the 1984 recipient of the Burroughs-Wellcome Toxicology Scholar Award.

\section{References}

1. Black, S. D., and M. J. Coon. 1986. Comparative structures of P-450 cytochromes. In Cytochromes P-450: Structure, Metabolism and Biochemistry. P. R. Ortiz de Montellano, editor. Plenum Publishing Corp., New York. 161-216.

2. Popper, H., M. A. Gerber, F. Schaffner, and I. J. Selikoff. 1979. Environmental hepatic injury in man. In Progress in Liver Diseases. H. Popper and F. Schaffner, editors. Grune \& Stratton Inc., New York. 605-638.

3. Nebert, D. W. 1979. Multiple forms of inducible drug-metabolizing enzymes: a reasonable mechanism by which any organism can cope with adversity. Mol. Cell. Biochem. 27:27-46.

4. Selye, H. 1971. Hormones and resistance. J. Pharm. Sci. 60:1-28.

5. Argus, M. F., C. Hoch-ligeti, J. C. Arcos, and A. H. Conney. 1978. Differential effects of beta-naphthoflavone and pregnenolone$16 \alpha$-carbonitrile on dimethylnitrosamine-induced hepatocarcinogenesis. J. Natl. Cancer Inst. 61:441-449.

6. Elshourbagy, N. A., and P. S. Guzelian. 1980. Separation, purification, and characterization of a novel form of hepatic cytochrome P-450 from rats treated with pregnenolone-16a-carbonitrile. J. Biol. Chem. 255:1279-1285.

7. Heuman, D. M., E. J. Gallagher, J. L. Barwick, N. A. Elshourbagy, and P. S. Guzelian. 1982. Immunochemical evidence for induction of a common form of hepatic cytochrome P-450 in rats treated with pregnenolone-16a-carbonitrile or other steroidal or non-steroidal agents. Mol. Pharmacol. 21:753-760.

8. Schuetz, E. G., S. A. Wrighton, J. L. Barwick, and P. S. Guzelian. 1984. Induction of cytochrome $P-450$ by glucocorticoids and in rat liver. I. Evidence that glucocorticoids and pregnenolone-16 $\alpha$-carbonitrile regulate de novo synthesis of a common form of cytochrome P-450. J. Biol. Chem. 259:1999-2006.

9. Wrighton, S. A., E. G. Schuetz, P. B. Watkins, P. Maurel, J. Barwick, B. S. Bailey, H. T. Hartle, B. Young, and P. S. Guzelian. 1985. Demonstration in multiple species of inducible hepatic cytochromes P-450 and their mRNAs related to the glucocorticoid inducible cytochrome P-450 of the rat. Mol. Pharmacol. 28:312-321.

10. Watkins, P. B., S. A. Wrighton, P. Maurel, E. G. Schuetz, G. Mendez-Picon, G. A. Parker, and P. S. Guzelian. 1985. Identification of an inducible form of cytochrome P-450 in human liver. Proc. Natl. Acad. Sci. USA. 82:6310-6314.

11. Molowa, D. T., E. G. Schuetz, S. A. Wrighton, P. B. Watkins, P. Kremers, G. Mendez-Picon, G. A. Parker, and P. S. Guzelian. 1986. Complete cDNA sequence of a cytochrome $\mathrm{P}-450$ inducible by glucocorticoids in human liver. Proc. Natl. Acad. Sci. USA. 83:5311-5315.

12. Hietanen, E. 1980. Oxidation and subsequent glucuronidation of 3,4-benzopyrene in everted intestinal sacs in control and 3-methylcholanthrene-pretreated rats. Pharmacology (Basel). 21:233-243.

13. Gennaro, A. R., R. Villanueva, Y. Sukonthaman, V. Vathanophas, and G. P. Rosemond. 1973. Chemical carcinogenesis in transposed intestinal segments. Cancer Res. 33:536-541.

14. Schuetz, E. G., G. A. Hazelton, J. Hall, P. B. Watkins, C. D. Klaassen, and P. S. Guzelian. 1986. Induction of digitoxigenin-monodigitoxoside UDP-glucuronosyltransferase by glucocorticoids and other inducers of cytochrome $\mathrm{P}-450 \mathrm{p}$ in primary monolayer cultures of adult rat hepatocytes and in human liver. J. Biol. Chem. 261:82708275.

15. Weiser, M. M. 1973. Intestinal epithelial cell surface membrane glycoprotein synthesis. I. An indicator of cellular differentiation. $J$. Biol. Chem. 248:2536-2541.

16. Bonkovsky, H. L., H. P. Hauri, U. Marti, R. Gasser, and U. A. Meyer. 1985. Cytochrome P-450 of small intestinal epithelial cells. Immunochemical characterization of the increase in cytochrome P-450 caused by phenobarbital. Gastroenterology. 88:458-467.

17. Van der Hoeven, T. A., and M. J. Coon. 1974. Preparation and properties of partially purified cytochrome $\mathrm{P}-450$ and reduced nico- 
tinamide adenine dinucleotide phosphate-cytochrome $P-450$ reductase from rabbit liver microsomes. J. Biol. Chem. 249:6302-6310.

18. Watkins, P. B., S. A. Wrighton, E. G. Schuetz, P. Maurel, and P. S. Guzelian. 1986. Macrolide antibiotics inhibit the degradation of the glucocorticoid-responsive cytochrome P-450p in rat hepatocytes in vivo and in primary monolayer culture. J. Biol. Chem. 261:6264-6271.

19. Laemmli, U. K. 1970. Cleavage of structural proteins during the assembly of the head of bacteriophage T4. Nature (Lond.). 227:680-685.

20. Beaune, P., P. Kremers, F. Letawe-Gujon, and J. E. Gielen, 1985. Monoclonal antibodies against human liver cytochrome P-450. Biochem. Pharmacol. 34:3547-3552.

21. Chirgwin, J. M., A. E. Przybyla, R. J. MacDonald, and W. I. Rutter 1979. Isolation of biologically active ribonucleic acid from sources enriched in ribonuclease. Biochemistry. 18:5294-5299.

22. Cleveland, D. W., M. A. Lopata, R. J. MacDonald, N. J. Cowan, W. J. Rutter, and M. W. Kirschner. 1980. Number of evolutionary conservation of $\alpha$ - and $\beta$-tubulin and cytoplasmic $\beta$ - and $\gamma$ actin genes using specific cloned cDNA probes. Cell. 20:95-105.

23. Nash, T. 1953. The colorimetric estimation of formaldehyde by means of the Hantzsch reaction. Biochem. J. 55:416-421.

24. Lowry, O. H., N. J. Rosebrough, A. L. Farr, and R. J. Randall. 1951. Protein measurement with the folin phenol reagent. J. Biol. Chem. 193:265-275.

25. Omura, T., and R. Sato. 1964. The carbon monoxide-binding pigment of liver microsomes. II. Solubilization, purification and properties. J. Biol. Chem. 239:2379-2385.

26. Wrighton, S. A., P. Maurel, E. G. Schuetz, P. B. Watkins, B. Young, and P. S. Guzelian. 1985. Identification of the cytochrome $\mathrm{P}-450$ induced by macrolide antibiotics in rat liver as the glucocorticoid responsive cytochrome P-450p. Biochemistry. 24:2171-2178.

27. Ryan, D. E., P. D. Thomas, L. M. Reik, and W. D. Levin. 1982. Purification, characterization and regulation of five rat hepatic microsomal cytochrome P-450 isozymes. Xenobiotica. 12:727-744.

28. Hostetler, K. A., S. A. Wrighton, and P. S. Guzelian. 1987. Immunochemical evidence for multiple steroid-inducible hepatic cytochromes $\mathrm{P}-450$ in the rat. Biochem. $J$. In press.

29. Kimura, S., F. Gonzales, and D. W. Nebert. 1986. Tissue-specific expression of the mouse dioxin-inducible $P_{1}-450$ and $P_{3}-450$ genes: differential transcriptional activation and mRNA stability in liver and extrahepatic tissues. Mol. Cell. Biol. 6:1471-1477.

30. Wrighton, S. A., P. E. Thomas, D. T. Molowa, M. Haniu, J. E. Shively, S. L. Maines, P. B. Watkins, G. Parker, G. Mendez-Picon, W. Levin, and P. S. Guzelian. 1986. Characterization of ethanol-inducible human liver N-nitrosodimethylamine demethylase. Biochemistry. 25:6731-6735.
31. Wrighton, S. A., P. E. Thomas, P. Willis, S. L. Maines, P. B. Watkins, W. Levin, and P. S. Guzelian. 1987. Purification of a human liver cytochrome P-450 immunochemically-related to several cytochromes $\mathrm{P}-450$ purified from untreated rats. J. Clin. Invest. In press.

32. Goldstein, J. A., and P. Linko. 1984. Differential induction of two 2,3,7,8-tetrachlorodibenzo-p-dioxin-inducible forms of cytochrome P-450 in extrahepatic versus hepatic tissues. Mol. Pharmacol. 25:185-191.

33. Gonzales, F. J., S. Byung-joon, and J. P. Hardwick. 1986. Pregnenolone-16 $\alpha$-carbonitrile-inducible P-450 gene family: gene conversion and differential regulation. Mol. Cell. Biol. 6:2969-2976.

34. Imondi, A. R., M. E. Balis, and M. Lipkin. 1969. Changes in enzyme levels accompanying differentiation of intestinal epithelial cells. Exp. Cell Res. 58:323-330.

35. Waxman, D. J., G. A. Dannan, and F. P. Guengerich. 1985. Regulation of rat hepatic cytochrome P-450: age-dependent expression, hormonal imprinting, and xenobiotic inducibility of sex-specific isoenzymes. Biochemistry. 24:4409-4417.

36. Lee, C. C., R. C. Anderson, and K. K. Chen. 1956. The excretory products of $\mathrm{N}$-methyl- $\mathrm{C}^{14}$-erythromycin in rats. J. Pharmacol. Exp. Ther. 117:274-280.

37. Holland, D. R., and J. F. Quay. 1976. Intestinal secretion of erythromycin base. J. Pharma. Sci. 65;417-419.

38. Mao, J. C., and P. L. Tardew. 1965. Demethylation of erythromycin by rabbit tissues in vitro. Biochem. Pharmacol. 14:1049-1058.

39. Murphy, P. J., T. L. Williams, R. E. McMahon, and F. J. Marshall. 1975. Metabolism of propionyl erythromycin lauryl sulfate. I. Fate of the propionyl of erythromycin moiety in the rat. Drug Metab. Dispos. 3:155-163.

40. Mather, L. E., K. L. Austin, C. R. Philpot, and P. J. McDonald. 1981. Absorption and bioavailability of oral erythromycin. Br. J. Clin. Pharmacol. 12:131-140.

41. Guengerich, F. P., M. V. Martin, P. H. Beaunne, P. Kremers, T. Wolff, and D. J. Waxman. 1986. Characterization of rat and human liver microsomal cytochrome $\mathrm{P}-450$ forms involved in nifedipine oxidation, a prototype for genetic polymorphism in oxidative drug metabolism. J. Biol. Chem. 261:5051-5060.

42. Beaune, P. H., D. R. Umbenhauer, R. W. Bork, R. S. Lloyd, and F. P. Guengerich. 1986. Isolation and sequence determination of a cDNA clone related to human cytochrome P-450 nifedipine oxidase. Proc. Natl. Acad. Sci. USA. 83:8064-8068.

43. Guengerich, F. P., D. Muller-Enoch, and I. A. Blair. 1986. Oxidation of quinidine by human liver cytochrome P-450. Mol. Pharmacol. 30:287-295. 